\title{
Moral Error Theory, Explanatory Dispensability and the Limits of Guilt
}

\author{
Silvan Wittwer (Harvard University)
}

[Note: this is a post-peer-review, pre-copyedit version of an article published in Philosophical Studies. The final authenticated version is available online at: https://doi-org.ezpprod1.hul.harvard.edu/10.1007/s11098-019-01355-4. Please cite the published version.]

\section{Abstract}

Recently, companions in guilt strategies have garnered significant philosophical attention as a response to arguments for moral error theory, the view that there are no moral facts and that our moral beliefs are thus systematically mistaken. According to Terence Cuneo (2007), Ramon Das (2016 \& 2017), Richard Rowland (2012 \& 2016) and others, epistemic facts would be just as metaphysically problematic (or 'guilty') as moral facts. But since epistemic error theory is implausible, arguments for moral error theory prove too much and should be rejected.

My aim is to argue that the success of this strategy is limited. In particular, the companions in guilt response fails against error-theoretic arguments motivated by concerns about explanatory dispensability, as recently developed by Richard Joyce (2005) and Jonas Olson (2014: Ch. 7). To succeed, the response would require a prima facie plausible argument to the effect that epistemic facts are metaphysically dubious because they, too, are explanatorily dispensable. But, as I show, any such argument proves self-effacing: its premise commits us to believing in epistemic facts, while its conclusion forces us to deny their existence. Consequently, companions in guilt strategies don't offer a panacea against arguments for moral error theory.

Key Words: Moral Error Theory, Companions in Guilt, Epistemic Reasons, Explanatory Dispensability, Evolutionary Debunking 


\section{Introduction}

Moral error theory is the view that there are no moral facts and that our moral beliefs are thus systematically mistaken. In response to arguments for this view, critics such as Terence Cuneo (2007), Ramon Das (2016 \& 2017), and Richard Rowland (2012 \& 2016) have recently turned towards companions in guilt strategies. According to their strategy, epistemic facts would be just as metaphysically problematic (or 'guilty') as moral facts. But, they contend, epistemic error theory is implausible. So, arguments for moral error theory seem to prove too much and should be rejected.

Companions in guilt strategies might be effective against error-theoretic worries about the categoricity or irreducibility of the normative. However, my aim is to argue that such strategies don't offer a panacea against arguments for moral error theory. In particular, their success doesn't translate to error-theoretic arguments motivated by concerns about explanatory dispensability, as recently developed by Richard Joyce (2005) and Jonas Olson (2014: Ch. 7). This is because, on reflection, explanatory dispensability seems problematic only for moral, yet not epistemic, facts. As a result, the latter cannot serve as companions in guilt for the former. In other words, there are limits to the metaphysical guilt of epistemic facts.

Here is my plan. $\$ 2$ introduces moral error theory and companions in guilt strategies. $\$ 3$ distinguishes between two importantly different motivations for moral error theory and develops an argument based on considerations of explanatory dispensability. $\$ 4$ presents a companions in guilt response and shows why it must fail, despite its initial promise. $₫ 5$ concludes and discusses some implications for the broader dialectic. 


\section{Moral Error Theory and Companions in Guilt Arguments}

According to moral error theory, there are no moral facts and all our atomic moral beliefs are thus systematically mistaken. ${ }^{1}$ Suppose you believe that dodging tax is morally wrong, that friendship is good or that reaching out to those who suffer is the kind thing to do. But, according to moral error theory, none of those moral beliefs are true because the corresponding moral facts don't exist.

A typical argument for moral error theory proceeds in two steps. The first step consists in a conceptual claim about the nature of moral discourse: moral discourse presupposes moral facts with feature F. Much of the literature focuses on categoricity as the feature in question. ${ }^{2}$ Moral facts are supposedly categorical in the sense that they obtain, if they do, independently of our aims, desires or interests. For instance, if it is indeed morally wrong to dodge tax, it is morally wrong for you to do so even if dodging tax was in your interest. ${ }^{3}$

The second step consists in a metaphysical claim that feature F is deeply metaphysically problematic and that there thus cannot be any such moral facts. Again, much of the literature focuses on moral categoricity. For instance, Richard Garner (1990) - loosely following J.L. Mackie (1977) - argues that categorical moral facts would have to be objectively prescriptive: when we think about moral facts, we think of them as prescribing or directing us to be or act in certain ways. But, he observes, '... it is hard to make sense of a demand without a demander, and hard to find a place for demands or demanders apart from human interests and conventions' (143). Similarly, Bart Streumer (2008, 2017) has more recently made the case that, for moral facts to be categorical, they would need to

\footnotetext{
${ }^{1}$ See Garner 1990, Joyce 2001, Mackie 1977, Olson 2014 and Streumer 2017.

2 More precisely, most of the literature concerns categoricity and/or irreducibility. For simplicity's sake, however, the exposition in the main text focuses on the former. We shall examine another feature, namely explanatory dispensability, in $\$ 3 \& \$ 4$ below.

3 Since both moral error theorists and robust moral realists who advance companions in guilt responses subscribe to the conceptual claim, I shall take its truth for granted henceforth.
} 
be irreducible to descriptive facts about our psychology. But that seems implausible, given Frank Jackson's (1998) supervenience argument. ${ }^{4}$ So, categorical moral facts don’t exist.

Together, these conceptual and metaphysical claims imply moral error theory. After all, even though moral discourse presupposes the existence of moral facts, they are too metaphysically problematic to obtain. So, there are no moral facts - and any moral beliefs purporting to represent them must be systematically mistaken.

Many find moral error theory intuitively dubious. To substantiate their assessment, some have recently turned towards companions in guilt strategies. Such strategies aim to show that error-theoretic arguments prove too much: if sound, they also establish implausible error-theoretic conclusions about, for example, epistemic facts. ${ }^{5}$

Any such companions in guilt strategy features two key components. The first component is the Parity Claim: putative epistemic facts, i.e. normative facts about what one has reason to believe or what one ought to believe given one's evidence, share the metaphysically problematic feature in question, namely categoricity. ${ }^{6}$ For example, based on the available statistical evidence on average human life expectancies, you should believe that you will most likely die before your $120^{\text {th }}$ birthday, even if you desperately don't want that to be the case. So, epistemic facts are categorical. But that seems just as metaphysically problematic for epistemic facts as it is for moral ones. For example, epistemic facts would have to be similarly objectively prescriptive, directing us to believe in certain ways. But, to quote Garner (1990) again, it is ‘...hard to find a place for demands or demanders

\footnotetext{
${ }^{4}$ Jackson (1998) famously argues that, given plausible claims about supervenience, descriptive predicates and property identity, there are no irreducibly normative properties. For a full defence against most critics, see Streumer 2008. ${ }^{5}$ My discussion focuses primarily on recent moral-epistemic companions in guilt arguments. See Bedke 2010, Cuneo 2007, Das 2016 \& 2017, Rowland 2012 \& 2016, Shafer-Landau 2003 and Stratton-Lake 2002. For discussion of moralmathematical companions in guilt arguments, see Clarke-Doane 2014, and Fletcher 2018 for moral-prudential.

${ }^{6}$ Henceforth, my discussion focuses - as is customary in the literature - on facts about epistemic reasons for belief, setting aside other kinds of epistemic facts (about, say, rationality, understanding or knowledge). Further, my discussion remains neutral with respect to the best account of what reasons are, as long as they are robustly normative (i.e. don't reduce to, say, facts about probability, non-normatively construed).
} 
apart from human interests and conventions' (143). Thus, the arguments for moral error theory also seem to establish epistemic error theory. If there are no categorical moral facts, there are no categorical epistemic facts either.

The second component is - what I shall call - the Falsity Claim: epistemic error theory is false (or, at least, highly implausible). This claim can be motivated in multiple ways. For instance, Terence Cuneo (2007: Ch. 4) does so by appeal to considerations of self-defeat and radical epistemological skepticism. In more detail, he argues that anyone denying the existence of categorical epistemic facts faces a deeply unattractive dilemma. Either, there is epistemic reason to believe the epistemic error theory - in which case the view is self-defeating. After all, the view would then presuppose the very sorts of entity (e.g. facts about what we rationally ought to believe) that it claims not to exist. ${ }^{7}$ Or, there is no epistemic reason to believe the epistemic error theory, yet it is true. In that case, though, there are not just no epistemic reasons to believe the view, but no epistemic reasons to believe anything. In other words, this implies radical epistemological skepticism, according to which no propositional attitudes can exhibit epistemic merit (e.g. justification) or demerit (e.g. irrationality). But such epistemological skepticism, just like self-defeat, is deeply theoretically unattractive. ${ }^{8}$ Therefore, we should reject epistemic error theory. ${ }^{9}$

Together, the Parity Claim and Falsity Claim imply that there is something wrong with the metaphysical premise of the argument for moral error theory above. According to this premise, categoricity is deeply metaphysically problematic - and there are thus no categorical moral facts.

\footnotetext{
${ }^{7}$ In what follows, I shall take this way of motivating the Falsity Claim for granted. For criticism, however, see Olson 2014: Ch. 8. He argues that there are hypothetical as well as (what we might call) practice-dependent epistemic reasons for belief. Importantly, epistemic error theory doesn't rule out those reasons. Thus, belief in epistemic error theory need not be self-defeating.

${ }^{8}$ For another argument to the effect that the radical skepticism entailed by epistemic nihilism is implausible, see Rowland 2012: 13-15.

${ }^{9}$ Cuneo (2007: 120f.) also notes a third implication of epistemic nihilism. If epistemic nihilism were true, there couldn't be any arguments for anything. This is because the premises of non-question-begging arguments offer evidential support (and thus articulate epistemic reasons) for the conclusion. But if there are no epistemic reasons, we couldn't have any evidential support and thus arguments.
} 
However, epistemic facts are also categorical, yet it would be implausible to deny their existence on those grounds alone. So, the categoricity of a given class of facts cannot be reason enough to eliminate them from our ontology. The argument for moral error theory is therefore insufficient to establish the truth of the view: that there are no moral facts.

The appeal to epistemic facts as companions in guilt strikes many as a promising response to errortheoretic arguments that are based on worries about categorical normativity. ${ }^{10}$ But that is not the only way to argue for moral error theory. Another argument is motivated by the concern that moral facts don't play a role in the best explanation of our moral beliefs. In the next two sections, I will present such an explanatory dispensability argument and argue that the prospects for a companions in guilt response look dim.

\section{Moral Error Theory and Explanatory Dispensability}

Not all arguments for moral error theory focus on categorical normativity as the metaphysically problematic feature of moral facts. Rather, moral error theorists such as Richard Joyce (2005: Ch. 6) and Jonas Olson (2014: Ch. 7) express concerns about the dispensability of moral facts to our best explanations of moral belief. In more detail, they offer - inspired by Gilbert Harman (1977), yet adding an increasingly popular evolutionary debunking twist - the following argument in support of moral error theory:

(1) Moral facts are dispensable to the best explanation of why people have the moral beliefs that they do.

\footnotetext{
${ }^{10}$ Consider, for example, the recent exchange between companions in guilt theorists such as Richard Rowland (2012, 2016) or Ramon Das $(2016,2017)$ and moral error theorists such as Christopher Cowie $(2014,2016)$ - during which, in my estimation, the former keep the upper hand. For more on Cowie's objections and how they differ from mine, see fn. 30 below.
} 
(2) If moral facts are dispensable to the best explanation of moral beliefs, we should believe that they don't exist.

(3) Therefore, we should believe that moral facts don't exist.

The first premise states that moral facts don't figure in the best explanation of our moral beliefs. According to both Joyce and Olson, the relevant explanation is evolutionary. Very roughly, we believe what we believe, morally speaking, in virtue of natural selection. For instance, we believe that incest is morally wrong or that we have special moral obligations to family members because thinking with those moral concepts proved adaptive or helped our ancestors survive. Now, the evolutionary explanation of our moral beliefs differs significantly from that of our perceptual beliefs about, say, mid-sized objects. It is overwhelmingly plausible that evolution has selected for their truth. After all, having true perceptual beliefs would have enhanced the fitness of our ancestors, helping them locate food and detect environmental threats. So, the evolutionary explanation of perceptual beliefs refers to perceptual facts. However, importantly, the evolutionary explanation of moral belief doesn't involve moral facts. After all, evolution hasn't selected for true moral beliefs, but for those that are most fitness-enhancing. In Joyce's (2005) words: '[w] hether we assume that the concepts right and wrong succeed in denoting properties in the world, or whether we think that they suffer from a referential failure that puts them on a par with the concepts witch and ghost, the plausibility of the hypothesis concerning how moral judgments evolved remains unaffected' (183).

The second premise says that, if moral facts are dispensable to the best explanation of moral beliefs, we should believe that they don't exist. This is simply an application of Ockham's razor, the methodological principle that we should deny the existence of superfluous components (e.g. entities, events, process) in theory-construction, i.e. components which are not required for the 
purpose of explaining the relevant data. ${ }^{11}$ Since the evolutionary explanation of moral belief renders moral facts superfluous, we should deny their existence - and therefore believe that they don’t exist.

From these two premises, it follows that we should believe that moral facts don't exist. ${ }^{12}$ Now, this conclusion doesn't establish moral error theory outright. After all, it doesn't articulate the metaphysical view that there are no moral facts. Rather, it only supports a form of moral skepticism, namely the less radical epistemological view that we should believe that they don't exist.

But that isn't problematic. On reflection, the moral skepticism that (3) articulates still favors the metaphysical claim that there are no moral facts. ${ }^{13}$ More specifically, most think that epistemic norms about what you ought to believe are connected to the truth. Of course, the exact nature of that truth-connection depends on our specific account of epistemic obligations for belief. On some accounts, the connection will be as strong as logical entailment. Consider the truth norm of belief: you should believe $\mathrm{p}$ only if $\mathrm{p}$ is true. ${ }^{14}$ On this account, it follows straightforwardly that, if you - all things considered - epistemically should believe that p, p is true. Similarly, take the knowledge norm of belief: you should believe $\mathrm{p}$ only if you know that $\mathrm{p} .{ }^{15}$ Of course, knowledge is factive: you can only know the truth. So, on this account, it also holds that, if you should believe $\mathrm{p}, \mathrm{p}$ is true. On other accounts, the connection between what we ought to believe and the truth might be weaker than logical entailment, but it will still favor p's truth. Take the following

\footnotetext{
${ }^{11}$ See Barnes 2000 for more on this anti-superfluity version of Ockham's razor. See Mogensen 2014: Ch. 4 for criticism of the application of Ockham's razor in the context of evolutionary explanations of morality.

${ }^{12}$ Strictly speaking, these premises don't quite establish the conclusion that we should believe that moral facts don't exist. Rather, as Joyce (2005: 184f.) concedes, that only follows if it can also be shown that moral facts are irreducible to natural facts. However, as mentioned in fn. 3, I shall take the truth of the conceptual claim for granted. According to that claim, moral discourse presupposes moral facts with feature F, where F concerns categoricity and/or irreducibility. I am grateful to an anonymous referee for pressing me on this point.

${ }^{13}$ I am grateful to an anonymous referee for forcing me to think more carefully about the relationship between (3) and moral error theory.

14 See, e.g., Shah 2003.

15 See, e.g., Williamson 2000.
} 
justification norm of belief: you should believe $\mathrm{p}$ only if you are justified in believing $\mathrm{p}$. Many think that epistemic justification is itself truth-conducive, if not factive. ${ }^{16}$ In other words, you are justified in believing $\mathrm{p}$ only if $\mathrm{p}$ is sufficiently likely to be true given your evidence. ${ }^{17}$ If that is correct, you should believe $\mathrm{p}$ only if $\mathrm{p}$ is sufficiently likely to be true given your evidence. Hence, if there is an epistemic obligation to believe $\mathrm{p}$, that favors that $\mathrm{p}$ is true - whether this favoring is a matter of entailment or likelihood.

What follows from these observations for our dialectic? It shows that the conclusion of the explanatory dispensability argument against moral facts does favor the metaphysical claim at the heart of moral error theory, namely that moral facts don't exist. After all, (3) says that we should believe that moral facts don't exist. But, as we have just seen, it is overwhelmingly plausible that epistemic obligations are connected to the truth. So, if you should believe that moral facts don't exist, that favors that they don't. On some accounts of epistemic obligation, the favoring relation will be strong: if you are obliged to believe that moral facts don't exist, they don't. On other accounts, the relation will be weaker: if you should believe that moral facts don't exist, it is sufficiently likely that they don't. Either way, though, the explanatory dispensability argument against moral facts turns out to be an argument for moral error theory. ${ }^{18}$

How might we respond to this error-theoretic argument? Many find its conclusion intuitively unpalatable. To substantiate that assessment, it seems attractive to resort again to a companions in guilt strategy, especially given its undeniable promise elsewhere. In the next section, I present a response along those lines, before arguing that it must eventually fail.

\footnotetext{
${ }^{16}$ Of course, if justification is factive (e.g. Sutton 2007), it follows straightforwardly that, if you should believe p, p is true.

17 See, e.g., Lehrer 1990: Ch. 8.

18 This is, of course, by no means the final word. Rather, it is a matter of active debate how exactly explanatory dispensability (or evolutionary debunking) arguments relate to moral error theory. For further discussion, see Joyce (forthcoming) and Olson (2019).
} 


\section{Explanatory Dispensability and the Limits of Guilt}

Recently, Terence Cuneo (2007: 103-7) has argued that companions in guilt strategies are also effective against error-theoretic arguments motivated by concerns about explanatory dispensability. While his discussion focuses more narrowly on an explanatory dispensability argument developed by Crispin Wright $(1992,1995)$, it is easy enough to see how his approach might work for other explanatory dispensability arguments such as the one presented above.

Recall that any companions in guilt strategy features two key components: the Parity Claim and the Falsity Claim. The latter can be established straightforwardly in our context. Since the explanatory dispensability argument in $\$ 3$ supports moral skepticism, the Falsity Claim must be interpreted accordingly, saying that epistemic skepticism is false (or, at least, highly implausible). But the view that we should believe in the non-existence of epistemic facts seems just as unattractive as epistemic error theory. After all, anyone committed to epistemic skepticism faces the following, familiar dilemma. ${ }^{19}$ Either, we should believe that there is epistemic reason to believe epistemic skepticism. In that case, though, the view appears to be self-defeating: it would tell us to believe in the very sort of entity, namely epistemic reasons, that it claims we should deny. Or, we shouldn't believe that there is epistemic reason to believe epistemic skepticism, yet it is true. In that case, though, we should deny the existence of any epistemic reasons, whether for the view or anything beyond..$^{20}$ In other words, we end up - yet again - with radical epistemological skepticism, according to which we must deny that propositional attitudes ever exhibit epistemic merit (e.g. justification) or demerit (e.g. irrationality). But such skepticism is - yet again - deeply theoretically unattractive. Therefore, we should reject epistemic skepticism as false or highly implausible. In

\footnotetext{
${ }^{19}$ Of course, one might think that epistemic skepticism, unlike epistemic error theory, is just blatantly incoherent: it tells us that we are epistemically obliged to deny the existence of epistemic obligations! If that is correct, the dilemma to follow in the main text won't be required to bring out the implausibility of the view and motivate the corresponding Falsity Claim. Further, if that is correct, epistemic skepticism might be even more unattractive than epistemic error theory, for the latter isn't blatantly incoherent.

${ }^{20}$ Assuming that this isn't just blatantly incoherent anyway. See fn. 19 above.
} 
what follows, I shall take this Falsity Claim for granted. But how can we substantiate the Parity Claim in our context? Or, why think that epistemic facts might be just as problematically dispensable to our best explanations of epistemic beliefs as moral facts to our best explanations of moral beliefs?

To answer that question, we can turn to an argument inspired by Sharon Street (2009). ${ }^{21}$ For her, the best explanation of our beliefs about epistemic reasons is also an evolutionary one. Very roughly, we hold such beliefs in virtue of natural selection. For instance, we believe that induction is reliable or wishful thinking is irrational because thinking with those epistemic concepts helped our ancestors survive. But, importantly, this kind of explanation doesn't avert to epistemic facts. ${ }^{22}$ After all, evolution didn't select for true epistemic beliefs, but for those that are most fitnessenhancing. Or, to quote Street: 'How does it help [for purposes of explaining our ancestors' survival] to say that creatures who made the normative judgment expressing the rule of induction grasped a fact about normative reasons?' (2009: 241). So, epistemic facts seem dispensable to our best, namely evolutionary, explanations of epistemic beliefs. But that seems just as metaphysically problematic for epistemic facts as it is for moral ones. If we should deny the existence of explanatorily dispensable moral facts, we should deny explanatorily dispensable epistemic facts as well. Thus, the argument for moral error theory presented in $\$ 3$ above also seems to establish epistemic skepticism. In this manner, we can establish the Parity Claim in our context.

But epistemic skepticism is false or highly implausible, according to the Falsity Claim. So, there must be something wrong with the explanatory dispensability argument for moral error theory.

\footnotetext{
${ }^{21}$ I say merely 'inspired' because Street is an epistemic constructivist, not error theorist. So, she doesn't take her argument to establish that there are no epistemic facts whatsoever. Rather, she takes it to establish that robust or mindindependent epistemic facts are dispensable to evolutionary explanations of epistemic beliefs - which is perfectly compatible with the existence of mind-dependent epistemic facts. But this wrinkle doesn't matter for our purposes. After all, both the error theorist and the robust moral realist deploying a companions in guilt strategy reject such minddependent normative facts as misrepresenting the nature of our normative concepts. (In other words, they both subscribe to the conceptual claim that moral discourse presupposes the existence of moral facts with feature F.) For both of them then, Street's argument would thus establish that there are no epistemic facts simpliciter.

$22 \mathrm{Or}$, at least, not to robust or mind-independent epistemic facts. See fn. 21 above.
} 
More precisely, since it is implausible to be skeptical about the existence of epistemic facts on grounds of explanatory dispensability alone, the explanatory dispensability of a given class of facts cannot be reason enough to question their place in our ontology. Therefore, the explanatory dispensability argument for moral error theory is insufficient to establish its conclusion: that we should believe that moral facts don't exist. Companions in guilt strategies thus don't just offer a promising response to error-theoretic arguments from moral categoricity, but also appear effective against arguments motivated by concerns that moral facts don't play a role in the best explanation of our moral beliefs. That would be bad news for moral error theory.

However, in my view, moral error theorists have little reason to worry. Such companions in guilt strategies cannot succeed against explanatory dispensability arguments, despite their initial promise and even if we grant the truth of the Falsity Claim. They falter because, on reflection, the Parity Claim turns out to be false in the context of explanatory dispensability.

To see why, it helps to clearly distinguish two issues: the putative explanatory indispensability of moral or epistemic facts - and whether that is indeed metaphysically problematic. For the sake of my argument, I am willing to grant that both moral and epistemic facts are dispensable to the best explanations of our respective beliefs about them. But that isn't enough to secure the Parity Claim yet. Rather, doing so also requires establishing that explanatory dispensability proves metaphysically problematic for both kinds of facts. ${ }^{23}$ That, though, cannot be done. Sure, the prima facie plausible explanatory dispensability argument in $\$ 3$ renders moral facts metaphysically problematic. ${ }^{24}$ But for epistemic facts to be equally metaphysically problematic, an analogous

\footnotetext{
${ }^{23}$ The reason is dialectical: the aim of the companions in guilt strategy is to respond to the explanatory dispensability argument by drawing an analogy to epistemic facts and arguing that we have good reason to believe in their existence. But drawing that analogy only works if epistemic facts are subject to the same threat as moral facts, i.e. if their explanatory dispensability is metaphysically problematic.

${ }^{24}$ Why think that a merely prima facie plausible argument suffices for that? Because a methodological view on which an argument needs to succeed outright to render a class of entities problematic seems too demanding to be plausible. After all, very few (skeptical) philosophical arguments ultimately succeed. Yet, most of us still think that those arguments raise a challenge worth engaging with.
} 
argument would have to be at least prima facie plausible as well. ${ }^{25}$ Based on the exposition of the strategy in the previous paragraph, that argument would read as follows:

(4) Epistemic facts are dispensable to our best explanations of why people have the epistemic beliefs that they do.

(5) If epistemic facts are dispensable to the best explanations of our epistemic beliefs, we should believe that they don't exist.

(6) Therefore, we should believe that epistemic facts don't exist.

However, as Jack Woods (2016: 14, 16f.) has recently observed (albeit in passing), arguments of this kind are self-effacing. ${ }^{26}$ To justify (5), we must assume the truth of Ockham's razor. That principle, though, encodes an epistemic obligation: it tells us that we should deny the existence of explanatorily superfluous entities. ${ }^{27}$ So, to motivate (5), we must accept or believe in the existence of at least one epistemic truth or fact, namely the one underwriting Ockham's razor. Meanwhile, (6) says that we should believe that epistemic facts don't exist. Thus, anyone running the argument above is forced into the following combination of doxastic attitudes: believing that epistemic facts exist, yet believing that they should believe that they don't. Such combinations, however, are plausibly irrational. After all, they violate the following variation of the Anti-Akrasia Constraint: it can never be rational to have high confidence in something like 'P, but I should believe not-P'. ${ }^{28}$

\footnotetext{
25 The explanatory dispensability of a class of facts doesn't strike me as brutely problematic. Rather, it only becomes so once we combine it with a methodological principle such as Ockham's razor. Doing that, though, amounts to putting forth an argument.

26 Woods (2016) avoids talk of dispensability and cashes out self-effacement more simply in terms of undermining justification (instead of impugning rationality, as I do below). He also raises his worry for a slightly more complex, namely burden-shifting, abductive argument. According to this argument, epistemic realists ought not continue holding their epistemic beliefs - unless they have additional, non-abductive reasons for doing so. However, I take it that his point carries over neatly to the argument discussed in the main text. After all, it boils down to the claim '...that some arguments against mathematical, logical and evaluatively normative [i.e. epistemic] beliefs presuppose their truth, so we cannot coherently doubt them by such methods' (2016: 20). See also Rinard forthcoming for a self-effacement argument against external world skepticism.

${ }^{27}$ For more on the epistemic formulation of Ockham's razor, see Baker 2016.

${ }^{28}$ Most of the literature on epistemic akrasia focuses on intuitively abominable conjunctions such as 'P, but I shouldn't believe that P'. But, if anything, 'P, but I should believe not-P' is even worse in that regard. Further, the latter is entailed by the former, assuming the overwhelmingly plausible principle that if you should believe not-p, you shouldn't
} 
So, anyone trying to reason their way through (4)-(6) ends up being irrational. As a result, the argument above cannot be prima facie plausible. ${ }^{29}$

What follows from the failure of this argument? It seems to show that we lack a prima facie plausible argument to the effect that epistemic facts are metaphysically dubious because they are explanatorily dispensable. But if we lack such an argument, we also lack reason to think that the explanatory dispensability of epistemic facts calls their metaphysical standing into question. That, in turn, is bad news for companions in guilt theorists. After all, if explanatory dispensability proves metaphysically troublesome only for moral, yet not epistemic, facts, they can hardly be on a par with respect to their problematic lack of explanatory credentials. In other words, the corresponding Parity Claim of the companions in guilt response must be false. But since the success of the companions in guilt strategy crucially hinges on the truth of this Parity Claim, it must fail as a response to the explanatory dispensability argument for moral error theory. So, moral error theorists needn't worry: their explanatory dispensability argument against moral facts remains on the table. Or, put more metaphorically: there are limits to the guilt of epistemic facts. While their categorical nature might be as problematic for epistemic as it is for moral facts, the same cannot be said for explanatory dispensability. ${ }^{30}$

believe that $\mathrm{p}$. (That principle, in turn, flows from a more general rational requirement not to believe contradictory contents). For an extended argument that epistemic akrasia is irrational, see Horowitz 2014.

${ }^{29}$ Is this kind of flaw plausibly called 'self-effacement'? Ultimately, that doesn't matter. Rather, it only matters that the above argument exhibits this flaw and thus isn't prima facie plausible, while the analogous argument against moral facts doesn't share this flaw and is prima facie plausible as a result. That alone is enough to undermine the Parity Claim, as I explain in the next paragraph of the main text.

${ }^{30}$ Note that my self-effacement worry is distinct and more forceful than Cowie's (2014) recent attack on the Parity Claim. He argues that the Parity Claim stands in tension with the Falsity Claim. In more detail, he thinks that, unlike epistemic error theory, moral error theory isn't plausibly self-defeating: '...the moral error theory would have the consequence that there are no moral reasons... But it would not have the consequence that there are no epistemic reasons' (411). But that undermines the Parity Claim: '[i]t undermines the parity premise because it entails that there is a sufficient reason for rejecting the epistemic error theory (namely, that it is self-defeating), that is not also a sufficient reason for rejecting the moral error theory.' (ibid.) Now, importantly, my worry is distinct, for it has nothing to do with the Falsity Claim, focusing instead on whether explanatory dispensability is metaphysically problematic for epistemic facts - and what that means for the Parity Claim. Further, my worry is also more forceful: unlike Cowie's, it doesn't mischaracterize our joint target, namely the Parity Claim. Cowie takes two classes of facts to be on a par (for the purposes of a companions in guilt strategy) only if they share both a metaphysically problematic feature $\mathrm{F}$ (such as, say, categoricity) and the grounds for believing that that given class of facts exists (namely self-defeat, in his case). But that is dialectically inappropriate, as Ramon Das (2016) and Richard Rowland (2016) have been quick to point 
Before concluding, let me briefly defend my claim that (4) -(6) amount to a self-effacing argument against two potential worries. Both are attempts to get by with less: by weakening (5), they promise to dissolve the tension arising from believing (5) and (6) at the same time. While the first worry questions whether (5) commits us to belief in genuine epistemic facts, the second worry reads this premise non-normatively.

The first worry questions whether accepting (5) really amounts to believing in the existence of genuine epistemic facts. Instead, couldn't (5) - and Ockham's razor motivating it - be underwritten by something less ontologically committing? For example, it might be that Ockham's razor is best understood as expressing a bypothetical epistemic obligation: we should believe that explanatorily superfluous entities don't exist - if we want true metaphysical beliefs (and denying that explanatorily superfluous entities exist is likely to help satisfy that desire of ours). ${ }^{31}$ But if that were correct, the explanatory dispensability argument against epistemic facts wouldn't be self-effacing. After all, (5) wouldn't commit us to belief in the exact kind of epistemic fact that (6) obliges us to deny the existence of. ${ }^{32}$

But the move just outlined isn't available to the companions in guilt theorist. Or, more precisely, it would be dialectically inappropriate for them to argue that the explanatory dispensability argument turns on anything other than genuine epistemic facts. To see why, consider our specific dialectic: in criticizing the self-effacement objection, the companions in guilt theorist responds to the moral

out. After all, moral error theory questions the existence of moral facts based on a putatively metaphysically problematic feature $\mathrm{F}$ (such as categoricity). In turn, the aim of a companions in guilt response is to show that another class of facts shares F (i.e. the Parity Claim), but that an error theory about those facts would be false (i.e. the Falsity Claim). So, the correct sense of moral-epistemic parity only involves the shared metaphysically problematic feature F, not also the grounds for believing that a given class of facts exists. Since my worry invokes exactly that sense, focusing on moral-epistemic parity strictly in terms of explanatory dispensability, it proves more forceful than Cowie's.

${ }^{31}$ For more on such 'normatively reducible' or - as I call them - non-genuine epistemic facts, see also Olson 2014: Ch. 8.

${ }^{32} \mathrm{I}$ am grateful to an anonymous referee for raising an issue along these lines. 
error theorist. But, importantly, the kind of moral error theorist pressing the self-effacement objection grants the Falsity Claim - and thus the existence of genuine epistemic facts. Instead, the target of the moral error theorist we are concerned with is the Parity Claim. More specifically, they take the self-effacement objection to show that, on reflection, moral and epistemic facts aren't on a par when it comes to problematic explanatory dispensability. And if the Parity Claim is false, that is itself enough to undermine the companions in guilt strategy, even if we grant the Falsity Claim. So, the moral error theorist advancing the self-effacement objection concedes the existence of genuine epistemic facts. For them, accepting (5) does really amount to believing in the existence of such facts. As a result, the explanatory dispensability argument against epistemic facts is selfeffacing: (5) commits us to belief in the exact kind of epistemic fact that (6) obliges us to deny the existence of.

The second worry develops an alternative formulation of the explanatory dispensability argument against epistemic facts. It reads:

$\left(4^{*}\right)$ Epistemic facts are dispensable to our best explanations of why people have the epistemic beliefs that they do.

$\left(5^{*}\right)$ If epistemic facts are dispensable to our best explanations, it is not the case that we should believe that epistemic facts exist.

$\left(6^{*}\right)$ Therefore, it is not the case that we should believe that epistemic facts exist.

But once spelt out along those lines, the argument is no longer self-effacing. ${ }^{33}$ After all, (5*) doesn't articulate an epistemic obligation to believe. Rather, it simply indicates the absence of an obligation to believe in existence of a given entity, namely epistemic facts. But if $\left(5^{*}\right)$ isn't epistemically

\footnotetext{
${ }^{33}$ I am grateful to an anonymous referee for raising this worry.
} 
normative, the premise - as well as the corresponding formulation of Ockham's razor motivating it - isn't plausibly underwritten by an epistemic truth or fact. And if that is correct, accepting $\left(5^{*}\right)$ doesn't mean assuming that at least one epistemic truth or fact exists. So, there is no tension between $\left(5^{*}\right)$ and $\left(6^{*}\right)$ : someone holding them at the same time wouldn't be irrational, for they wouldn't violate the Anti-Akrasia Constraint.

On reflection, however, $\left(4^{*}\right)-\left(6^{*}\right)$ is an implausible formulation of the explanatory dispensability argument. To start with, $\left(5^{*}\right)$ overlooks the distinctively normative role that considerations of explanatory dispensability and Ockham's razor play in how we form beliefs about what exists. To see that, consider our beliefs about the existence of witches. Intuitively, finding out that witches are dispensable to our best explanations of why we hold beliefs about them doesn't merely indicate that we have no obligation to believe that witches exist. Rather, learning that witches are explanatorily dispensable makes it obligatory for us to believe in their non-existence. In other words, Ockham's razor is a normative principle: it tells us that we should deny the existence of explanatorily superfluous entities, not just that it is not the case that we should believe in them. This point is widely accepted in the literature on ontological parsimony. ${ }^{34}$

But I can say something even stronger. An appeal to a non-normative premise such as $\left(5^{*}\right)$ would be dialectically inappropriate for the companions in guilt theorist. After all, for their strategy to be warranted in the first place, explanatory dispensability considerations must pose a genuine skeptical threat to the existence of normative facts, whether moral or epistemic. But such considerations raise a proper challenge only if the explanatory dispensability of a given entity compels us to deny its existence. If explanatory dispensability merely alerted us to the absence of an obligation to believe in normative facts, that would hardly generate pressure to defend their ontological status.

\footnotetext{
${ }^{34}$ See, for example, Baker 2016, Barnes 2000 or Schaffer 2015.
} 
So, companions in guilt theorists must understand explanatory dispensability considerations (and Ockham's razor) as normatively weighty. In other words, it would be dialectically improper for companions in guilt theorists to rely on the non-normative premises such as $\left(5^{*}\right)$ - and its moral analogue $\left(2^{*}\right)$ - in formulating explanatory dispensability arguments. As a result, $\left(4^{*}\right)-\left(6^{*}\right)$ amounts to an implausible formulation and should be rejected.

\section{Conclusion}

My aim was to argue that companions in guilt strategies don't offer a panacea against moral error theory. While they might be effective against error-theoretic arguments based on worries about the categoricity of the normative, their promise doesn't translate to error-theoretic arguments motivated by concerns about explanatory dispensability. My reasoning was straightforward: on reflection, explanatory dispensability seems metaphysically problematic only for moral, yet not epistemic, facts. To be metaphysically problematic for epistemic facts, we would need a prima facie plausible explanatory dispensability argument against them. But any such argument turns out to be self-effacing: its premise commits us to believing in epistemic facts, while its conclusion forces us to deny their existence. So, epistemic facts cannot serve as companions in guilt for moral facts in that respect. In other words, there are limits to the metaphysical guilt of epistemic facts.

Let me close with an implication and a caveat. First, my objection plausibly generalizes to other putative companions in guilt for moral facts. Take, for instance, mathematical facts: some have argued that error-theoretic or otherwise skeptical arguments against moral facts, if successful, also establish implausible error-theoretic or skeptical conclusions about mathematical facts. ${ }^{35}$ But if my objection is on track, such strategies are unlikely to achieve much in the context of explanatory dispensability arguments. After all, any analogous explanatory dispensability argument against

\footnotetext{
${ }^{35}$ For discussion, see Clarke-Doane 2014, McGrath 2014 and Scanlon 2014: Ch. 2.
} 
mathematical facts threatens to be self-effacing yet again, given that it presupposes belief in mathematical facts in its premise and dictates denying their existence in its conclusion. More precisely, its second premise will appeal to Ockham's razor. But to make sense of that principle, we must - inter alia - believe in the existence of numbers to count the entities involved in a given explanation of mathematical belief as well as compare them to rival explanations. ${ }^{36}$ So, since any explanatory dispensability argument against mathematical facts risks self-effacement, the dispensability of mathematical facts to the best explanation of our mathematical beliefs doesn't render those facts metaphysically problematic. Again, opponents of moral error theory would struggle to establish the Parity Claim. In light of this further failure, we have reason to think that companions in guilt strategies are more generally flawed as a response to explanatory dispensability arguments for moral error theory.

Second, a caveat: I take my paper to have shown that companions in guilt strategies are toothless as a response to the explanatory dispensability argument for moral error theory. That, though, doesn't mean that there aren't any successful (and perhaps more direct) responses in the offing. For example, critics might argue that evolutionary explanations don't exclude moral facts ${ }^{37}$ or that moral facts, despite not figuring in the best explanations of our moral belief, are nonetheless indispensable to practical deliberation. ${ }^{38}$ While assessing these potential responses amounts to a worthwhile endeavour, doing so goes well beyond the scope of my paper.

\section{Bibliography}

Baker, Alan (2008). Simplicity. Stanford Encyclopedia of Philosophy.

Barnes, E. C. (2000). Ockham's razor and the anti-superfluity principle. Erkenntnis 53 (3):353-374.

\footnotetext{
${ }^{36}$ See Woods 2016: 12-14.

${ }^{37}$ See Mogensen 2015 \& 2016.

38 See Enoch 2011 and McPherson \& Plunkett 2015 for criticism.
} 
Bedke, Matthew S. (2010). Might All Normativity Be Queer? Australasian Journal of Philosophy 88 (1):41-58.

Clarke-Doane, Justin (2014). Moral Epistemology: The Mathematics Analogy. Noûs 48 (2):238-255.

Cowie, C. (2014). Why Companions in Guilt Arguments Won't Work. Pbilosophical Quarterly 64 (256): 407422.

Cowie, C. (2016). Good News for Moral Error Theorists: A Master Argument Against Companions in Guilt Strategies. Australasian Journal of Philosophy 94 (1): 115-130.

Cuneo, Terence (2007). The Normative Web: An Argument for Moral Realism. Oxford University Press.

Das, Ramon (2016). Why companions in guilt arguments still work: Reply to Cowie. Philosophical Quarterly: $152-60$.

Das, Ramon (2017). Bad News for Moral Error Theorists: There Is No Master Argument Against Companions in Guilt Strategies. Australasian Journal of Philosophy 95 (1): 58-69.

Enoch, David (2011). Taking Morality Seriously: A Defense of Robust Realism. Oxford University Press UK.

Fletcher, Guy (2018). Pain for the Moral Error Theory? A New Companions-in-Guilt Argument. Australasian Journal of Philosophy: 474-82.

Garner, Richard T. (1990). On the genuine queerness of moral properties and facts. Australasian Journal of Pbilosophy 68 (2):137 - 146.

Harman, Gilbert (1977). The Nature of Morality: An Introduction to Ethics. Oxford University Press. 
Horowitz, Sophie (2014). Epistemic Akrasia. Noûs 48 (4):718-744.

Jackson, Frank (1998). From Metaphysics to Ethics: A Defence of Conceptual Analysis. Oxford University Press.

Joyce, Richard (2001). The Myth of Morality. Cambridge University Press.

Joyce, Richard (2005). The Evolution of Morality. Bradford.

Joyce, Richard (forthcoming). Moral and epistemic normativity: The guilty and the innocent. In: C. Cowie \& R. Rowland (eds.), Companions in Guilt Arguments in Metaetbics (Routledge, forthcoming).

Lehrer, Keith (1990). Theory of Knowledge. Routledge.

Mackie, John L. (1977). Ethics: Inventing Right and Wrong. Penguin Books.

McGrath, Sarah (2014). Relax? Don't do it! Why Moral Realism Won't Come Cheap. Oxford Studies in Metaethics 9: 186-214.

McPherson, Tristram \& Plunkett, David (2015). Deliberative Indispensability and Epistemic Justification. Oxford Studies in Metaethics 10: 104-34.

Mogensen, Andreas L. (2014). Evolutionary Debunking Arguments in Ethics. DPhil Thesis. Oxford University.

Mogensen, Andreas L. (2015). Evolutionary debunking arguments and the proximate/ultimate distinction. Analysis 75 (2):196-203. 
Mogensen, Andreas L. (2016). Do evolutionary debunking arguments rest on a mistake about evolutionary explanations? Pbilosophical Studies 173 (7):1799-1817.

Olson, Jonas (2014). Moral Error Theory: History, Critique, Defence. Oxford University Press.

Olson, Jonas (2019). What can debunking do for us? Ratio.

Rowland, Richard (2012). Moral Error Theory and the Argument from Epistemic Reasons. Journal of Ethics and Social Philosophy 7 (1): 1-24.

Rowland, Richard (2016). Rescuing Companions in Guilt Arguments. Pbilosophical Quarterly: 161-71.

Scanlon, T. M. (2014). Being Realistic About Reasons. Oxford University Press.

Schaffer, Jonathan (2015). What Not to Multiply Without Necessity. Australasian Journal of Philosophy 93 (4): 644-664.

Shafer-Landau, Russ (2003). Moral Realism: A Defence. Oxford University Press.

Shah, Nishi (2003). How truth governs belief. Philosophical Review 112 (4): 447-482.

Stratton-Lake, Philip (ed.) (2002). Ethical Intuitionism: Re-Evaluations. Oxford University Press UK.

Street, Sharon (2009). Evolution and the normativity of epistemic reasons. Canadian Journal of Philosophy 39 (S1): 213-248.

Streumer, Bart (2008). Are There Irreducibly Normative Properties? Australasian Journal of Philosophy 86 (4):537-561. 
Streumer, Bart (2017). Unbelievable Errors: An Error Theory About All Normative Judgments. Oxford University Press.

Sutton, Jonathan (2007). Without Justification. MIT Press.

Williamson, Timothy (2000). Knowledge and its Limits. Oxford University Press.

Woods, Jack (2016). Mathematics, Morality, and Self-Effacement. Noûs.

Wright, Crispin (1992). Truth and Objectivity. Harvard University Press.

Wright, Crispin (1995). Truth in ethics. Ratio 8 (3):209-226. 